\title{
Cenas do próximo capítulo: análise dos modelos de família construídos nas telenovelas
}

\author{
Scenes of the next chapter: analysis of family \\ models built in soap operas
}

\section{Robson Souza dos Santos ${ }^{[a]}$, Valquíria Michela John ${ }^{[\mathrm{b}]}$, Camila Guerra ${ }^{[\mathrm{c}]}$}

[a] Jornalista, Mestre em Literatura Brasileira, professor dos cursos de Jornalismo e Relações Públicas da Universidade do Vale do Itajaí (UNIVALI), Itajaí, SC - Brasil, e-mail: souza@univali.br

[b] Jornalista, Mestre em Educação, Doutoranda em Comunicação e Informação pela Universidade Federal do Rio Grande do Sul (UFRGS), professora do curso de Jornalismo da Universidade do Vale do Itajaí(UNIVALI), Itajaí, SC - Brasil, e-mail: val@univali.br

[c] Acadêmica do Curso de Comunicação Social - Jornalismo da Universidade do Vale do Itajaí (UNIVALI), pesquisadora do grupo Monitor de Mídia, Itajaí, SC - Brasil, e-mail: camiguerrinha@hotmail.com

\section{Resumo}

Há 50 anos a telenovela faz sucesso no Brasil. O gênero, que reúne em sua composição as características dos seus antepassados como o melodrama, o folhetim e a soap opera americana, influencia o comportamento dos telespectadores e pauta discussões sociais a partir dos temas que aborda. Por tratar-se de um dos mais importantes componentes da cultura brasileira e estar inserida na televisão, meio de maior alcance nacional, foi utilizada como base para este estudo, que analisou como são retratadas as famílias nas telenovelas da Globo e da Record. Esta pesquisa apurou se há ou não semelhanças entre os modelos familiares da atualidade, a partir da definição antropológica de família e dos indicadores do IBGE, em relação aos que se fazem presentes nas telenovelas. Para traçar os perfis das famílias foram considerados o tamanho, o modelo, a chefia e o cenário matrimonial presente em cada uma das tramas avaliadas.

Palavras-chave: Família. Telenovela. Rede Globo. Rede Record.

\section{Abstract}

For 50 years the soap opera has been popular in Brazil. The genres, which includes in its composition the characteristics of their ancestors as melodrama, serial novel and soap opera, influences the behavior of viewers and staff from social discussions of the issues it addresses. Because it is one of the most important components of Brazilian culture and is built into the television, through greater national reach, was used as the basis for this study, which examined how families are portrayed in soap operas of the Globo and the Record. This research examined whether or not there are similarities between family patterns of today, from the anthropological definition of family and indicators of IBGE, for which they are found in soap operas. To trace the profiles of the families were considered the size, model, leadership and marriage this scenario in each of the plots studied.

Keywords: Family. Soap opera. Rede Globo. Rede Record. 


\section{Breves notas sobre a história da telenovela}

Há mais de 50 anos, a telenovela brasileira segue contando histórias do dia a dia da nação. Misturando as "receitas" de seus antepassados - o melodrama, o folhetim e a soap opera americana - Ela ajuda a influenciar padrões de comportamento, práticas culturais e de consumo, pautando as discussões diárias do cidadão brasileiro.

É praticamente unânime entres os estudiosos da telenovela (não apenas a brasileira) que ela tenha sua principal origem na reinterpretação do romance-folhetim, sendo muitas vezes chamada de "folhetim eletrônico". Para muitos autores, a estrutura narrativa da telenovela é a soma da fórmula encontrada nos folhetins do século XIX com mecanismos do melodrama, ambos tendo origem em meio às revoluções que dominaram a Europa naquele período.

Conforme Martín-Barbero (2003), o melodrama - "teatro do povo" - era encenado nos modos dos espetáculos de feira, recuperando temas da literatura oral, especialmente os contos de medo e de mistério. Ele estabelecia um laço de cumplicidade com o público, que em geral não sabia ler e, portanto, procurava nas cenas grandes ações e paixões, sendo esse forte sabor emocional o que demarcaria definitivamente o gênero, colocando-o ao lado do popular.

Em relação ao outro antepassado da telenovela, o folhetim, Cristina Costa (2000) o define como sendo uma narrativa "árabe folhetinesca", pelo seu modo de trabalhar com histórias seriadas, encontrando no jornal o espaço apropriado para sua difusão e consequente "estratégia de marketing" para atrair os leitores. ${ }^{1}$

Em 1951, a telenovela aporta no Brasil, quando é lançada, pela TV Tupi de São Paulo, Sua vida me pertence, de Walter Forster. Entretanto, é em 1963 que surge a primeira telenovela diária. A novela 2-5499 Ocupado foi ao ar pela TV Excelsior, com autoria do argentino Alberto Migré, na qual estrelaram Glória Menezes e Tarcísio Meira. Posteriormente, em
1967, com a hegemonia da telenovela já estabelecida, é veiculado o maior sucesso do gênero na história da programação televisiva brasileira: Direito de nascer. Inicialmente concentrada no horário das 20h, a telenovela foi ampliando sua propagação e seu público. Destinada de início às donas de casa, ao longo de seus 45 anos de existência, ${ }^{2}$ a telenovela brasileira passou a destinar-se a todas as faixas etárias, classes sociais e sexos, adotando temáticas específicas para atingir um número cada vez maior de espectadores.

A definição dos horários das telenovelas está totalmente ligada à Rede Globo. Já na década de 1960, a emissora instituiu quatro horários de forma a atender às várias faixas etárias e aos perfis de seus espectadores. Como explica Fernandes (1997), a Globo definiu que o horário das $18 \mathrm{~h}$ destinava-se às tramas água com açúcar que reproduziam a literatura clássica brasileira para os jovens; às 19h, comédias românticas; às $20 \mathrm{~h}$, horário nobre, eram discutidos assuntos mais complexos, temas sociais que tinham identificação do público e, às $22 \mathrm{~h}$, eram apresentadas as críticas e reflexões sociais. Atualmente, a definição das temáticas parece a mesma e a novela das $20 \mathrm{~h}$ soma características também da que era veiculada às $22 \mathrm{~h}$, passando a ser exibida por volta das $21 \mathrm{~h}$. Além da trama das $18 \mathrm{~h}$, a emissora exibe a novela teen Malhação, ${ }^{3}$ às $17 h 30$.

\section{A que se deve o sucesso das telenovelas?}

É importante ter claro que a ficção, por mais "inventada" que seja a história contada/narrada, sempre tem um vínculo com a realidade. A telenovela narra histórias que buscam inspirações na vida real, tornando os "territórios de ficcionalidade" interpenetráveis e o limiar entre ficção e realidade extremamente tênue.

Os estudiosos da telenovela, como MartínBarbero, qualificam a composição dos gêneros dessa narrativa como sendo híbrida. Ou seja, cada telenovela "mistura" em seu enredo o arcaico e o

\footnotetext{
1 Os capítulos eram sempre interrompidos em momentos de "clímax", levando o leitor a comprar o jornal do dia seguinte.

2 Embora sejam produzidas desde 1951, considera-se como marco o ano de 1963, com o início das telenovelas diárias.

3 Apesar de ser chamada de novela, Malhação segue um formato similar ao das séries norte-americanas, já que trabalha com "temporadas".

4 CALVINO apud LOPES, 2002.
} 
moderno. Nessa narrativa está presente a estrutura original do melodrama, com suas quatro figuras essenciais (o herói, o vilão, a vítima e o bobo), associada a diversos outros gêneros: comédia, tragédia, western, musical, suspense, terror, ficção científica. Combinado à estrutura narrativa popular, esse "hibridismo" dá a essência da ficção seriada televisiva, em especial, a telenovela. Com essa fórmula, ocorre a interação entre a narrativa apresentada e o seu espectador, já que, ao combinar diversos gêneros, tendo como inspiração a "realidade" dos espectadores, a telenovela propicia o "mergulho" e o fascínio do receptor em suas histórias.

A familiaridade ocorre porque as histórias da telenovela buscam sua inspiração na vida cotidiana, sendo sempre uma "fatia" dessa realidade, uma construção imaginária, mítica e arquetípica, mas que se confunde com ela por tratar dos assuntos comuns aos seus espectadores. Para obterem tal efeito, as telenovelas dramatizam o cotidiano, com todos os seus problemas, conflitos, resoluções e comportamentos. É isso que lhes confere sua atualidade e sua veracidade.

As narrativas das telenovelas são, ao mesmo tempo, abertas e fechadas. ${ }^{5}$ Fechadas pela sua defesa dos valores tradicionais (como a família e a heterossexualidade, por exemplo) e abertas por não serem apresentadas tramas e situações lineares, simples, mesmo porque seus personagens podem modificarse conforme a aceitação do público.

Lopes, Borelli e Resende (2002) consideram que as telenovelas podem ser analisadas a partir da hipótese de agenda setting, ao proporem o debate de certos temas, ao organizarem a agenda pública de discussões quepermeiam a sociedade. Essa mescla entre o "abertoe o fechado" é uma das receitas para o sucesso e a difusão da narrativa de ficção seriada televisiva.

A principal característica da narrativa ficcional é o seu caráter de verossimilhança e é este o principal componente da estrutura da telenovela. O grande sucesso, a conquista de popularidade da telenovela brasileira, deu-se a partir do momento em que a realidade e o dia a dia brasileiro foram incorporados aos capítulos diários oferecidos para a distração do público. A primeira experiência foi da TV Tupi, em 1969, com Beto Rockfeller, que rompeu com o círculo melodramático, introduzindo o humor e a descontração na trama apresentada.
Como aponta Marques de Melo (1988), esse novo modelo exerceu fascínio sobre os telespectadores porque eles estavam acostumados a "consumir produções romanescas importadas" e com a "nova" telenovela vislumbraram a possibilidade de exercitar "sua fantasia cotidiana através de produções artísticas em que podiam reconhecer-se e ao seu meio ambiente". Esse modelo foi imediatamente adotado pela Rede Globo, que investiu tecnicamente na produção da telenovela, montando estúdios, cidades cenográficas e rapidamente consolidando-se como a maior produtora do gênero.

O segredo da telenovela brasileira, sobretudo da Rede Globo, é definido por Sodré (1977) como o resultado da combinação entre a "ficção sem fantasia" e a "moral doméstica". É o exercício efetivo da verossimilhança ou até além dela, operando o sincretismo entre o real e o imaginário, tornando-o homogêneo. A ficção atua como espelho do real, ajustando os conteúdos ideológicos a sentimentos, costumes e tendências que já existem socialmente.

\section{Conceitos e definições de família}

O termo família deriva do latim famulus, que significa escravo doméstico. Essa denominação surgiu na Roma Antiga para nomear um novo grupo social que nasceu entre as tribos latinas. Segundo Engels (1995, p. 61), “a expressão foi inventada pelos romanos para designar um novo organismo social, cujo chefe mantinha sob seu poder a mulher, os filhos e certo número de escravos, com pátrio poder romano e o direito de vida e morte sobre eles". Ou seja, família era o conjunto de escravos pertencentes ao mesmo homem.

O conceito de família está diretamente ligado aos valores sociais que regem cada sociedade e ao período histórico em que estas se encontram. Não há, portanto, um modelo ou conceito definitivo do que é família. Essa noção será diferente, inclusive, a partir das próprias ciências que se dedicam ao estudo desse agrupamento social, como a Antropologia e a Sociologia. Do ponto de vista da Antropologia, a família consiste em um grupo de pessoas que possuem ligação por diferentes níveis de parentesco e

5 O conceito de Obra Aberta foi proposto por Umberto Eco (1968). 
que, normalmente, residem no mesmo local. Em geral, é considerada a essência das sociedades por ser encontrada nas mais diversas civilizações, ainda que com estrutura e organizações distintas.

Inicialmente, a família surgiu como forma de garantir a sobrevivência e a reprodução da espécie e, posteriormente, configurou-se como um grupo social. Este ainda tem como responsabilidades garantir o sustento da prole, educar e socializar as crianças, além de cuidar dos idosos e inválidos da família, sempre se levando em conta que essas atribuições serão diferentes conforme as sociedades em que se inserem.

Segundo Marconi e Presotto (2001), em uma classificação de base antropológica, a família pode ser:

Elementar ou nuclear: constituída por um homem, sua esposa e seus filhos, é tida como passageira, pois no decorrer dos anos com a saída dos filhos torna-se menor, correndo até o risco de desaparecer com a morte dos pais.

Extensa ou múltipla: unidade composta por mais de duas gerações de famílias elementares, ligadas por laços de sangue.

Composta ou complexa: família formada por três ou mais cônjuges. Pode existir em sociedades monogâmicas, quando ocorre um segundo casamento, que origina madrastas, padrastos e enteados; ou poligâmicas, quando um homem ou uma mulher possuem mais de um cônjuge.

Conjugada-fraterna: relação existente entre dois irmãos e seus respectivos filhos e esposas.

Fantasma: família constituída por mulher, marido, filhos e o fantasma. Nessa composição é o irmão mais velho da mãe que desempenha a função de pai das crianças.

Ainda que não se possa desenvolver uma noção universal de família, o modelo de família nuclear é o que impera em nossas sociedades e é costumeiramente visto como o padrão de "normalidade" da constituição desse grupo social. Essa ideia de normalidade pode levar ao julgamento de que outros modelos familiares não são compatíveis com a moral do grupo. Entretanto, ainda que muitas vezes de forma lenta e gradual, toda sociedade se transforma, passa por uma constante reelaboração, o que é uma característica inerente à sua cultura. Assim, também a noção e a estrutura da família vêm transformando-se constantemente.

\section{Composição familiar no Brasil}

Um dos exemplos desse processo está no papel exercido pelas mulheres na organização familiar brasileira, e em boa parte das sociedades, fruto do que se convencionou chamar de revolução feminina. O movimento de mulheres no Brasil trouxe novas possibilidades à composição familiar: o divórcio, a implementação do uso de anticoncepcionais e preservativos, além da efetiva inserção da mulher no mercado de trabalho. Esses acontecimentos propiciaram independência à mulher e a possibilidade dela tornar-se, por exemplo, chefe de família.

Outra composição familiar que vem surgindo no País é a união entre pessoas do mesmo sexo. Nesse arranjo teremos dois homens ou duas mulheres dentro de uma união estável, com a possibilidade de adotar uma criança. Isso demonstra que a família, como outras instituições da organização social brasileira, está em processo de mudança, acompanhando as transformações que o mundo está atravessando. Entre outras mudanças na família brasileira, está aumentando a incidência de famílias em que apenas um dos pais se faz presente. Segundo o Instituto Brasileiro de Geografia e Estatística (IBGE, 2007), $47 \%$ das famílias brasileiras fazem parte dessa nova realidade. Nesse caso, os pais ou mães podem ser solteiros ou terem um segundo casamento, em que se estabelece a relação de padrastos ou madrastas com enteados.

O IBGE aponta também a diminuição do tamanho das famílias brasileiras nas últimas décadas. Segundo a Pesquisa Nacional por Amostra de Domicílio (PNAD) de 2006, a média de pessoas fica em torno de 3,2 por família. A redução pode ser comprovada em todas as classes sociais, embora com percentuais diferentes. Houve também diminuição no número de famílias com filhos, que passou de 73,3\% em 1996 para 67,6\% em 2006.

\section{A família no contexto das telenovelas}

Para a realização desta análise, primeiramente, foram mapeadas as novelas dos principais canais da TV aberta: Rede Bandeirantes, Rede Globo, Rede Record e Sistema Brasileiro de Televisão (SBT), em exibição no primeiro semestre de 2008 (Tabela 1). 
Tabela 1 - Novelas em exibição por emissora

\begin{tabular}{cccc}
\hline Novela & Emissora & Horário & Classificação \\
\hline Amores e intrigas & Rede Record & $21 \mathrm{~h}$ & Inédita \\
Beleza pura & Globo & $19 \mathrm{~h}$ & Inédita \\
Cabocla $^{6}$ & Globo & $18 \mathrm{~h}$ & Reprise \\
Caminhos do coração & Rede Record & $22 \mathrm{~h}$ & Inédita \\
Chiquititas & SBT & $20 \mathrm{~h}$ & Inédita \\
Dance, dance, dance & Band & $20 \mathrm{~h} 15 \mathrm{~min}$ & Inédita \\
Desejo proibido & Globo & $18 \mathrm{~h}$ & Inédita \\
Duas caras & Globo & $21 \mathrm{~h}$ & Inédita \\
Lalola & SBT & $21 \mathrm{~h}$ & Inédita - Mexicana \\
O privilégio de amar & SBT & $17 \mathrm{~h}$ & Reprise - Mexicana \\
\hline
\end{tabular}

A Rede'TV foi desconsiderada desse levantamento por não produzir novelas. Foram selecionadas, para a análise dos modelos de família, apenas as novelas da Rede Globo e da Rede Record, por serem as duas emissoras de maior audiência. $\mathrm{Na}$ Tabela 2, estão destacadas as novelas pesquisadas e algumas de suas características.
$\mathrm{Na}$ análise, foram considerados o tamanho, o modelo e o exercício de chefia de cada família, bem como o cenário matrimonial que compõe os núcleos principais das tramas. Essas categorias foram elaboradas a partir da classificação feita por Marconi e Presotto (2001) e associadas às categorias utilizadas pelo IBGE. Entretanto, ao contrário do IBGE, que

Tabela 2 - Telenovelas analisadas

\begin{tabular}{cccc}
\hline Novela & Emissora & Autor & Audiência $^{7}$ \\
\hline Amor e intrigas & Record & Gisele Joras & 13 Pontos \\
Beleza pura & Globo & Andréa Maltarolli & 28 Pontos \\
Cabocla & Globo & Benedito Ruy Barbosa & 14 Pontos \\
Caminhos do coração & Record & Tiago Santiago & 19 Pontos \\
Desejo proibido & Globo & Walther Negrão & 24 Pontos \\
Duas caras & Globo & Aguinaldo Silva & 45 pontos \\
\hline
\end{tabular}

considera como família pessoas que residem no mesmo domicílio independente de laços de parentesco, nesta análise partiu-se, como já dito, da noção antropológica de família, portanto, apesar de adotar as categorias do IBGE, foram analisadas apenas as composições familiares com laço de parentesco (consanguíneo ou não). A apreciação das telenovelas foi realizada no intervalo de 21 a 28 de abril de 2008. Vale a pena ressaltar que, além do IBGE, as categorias de análise basearam-seno estudo "Telenovela e família no Brasil", desenvolvido por Fadul (1999). Na sequência, a análise de cada uma das telenovelas estudadas.

\section{Amor e intrigas}

Como o próprio nome sugere, a trama da novela gira em torno de amores e intrigas. A personagem principal é Alice, que, na trama, sai de Ouro Preto, MG, em busca de sua irmã, Valquíria, que aplicou um grande golpe na família. Quando chega ao Rio de Janeiro, Alice conhece Felipe e ambos apaixonam-se. Entretanto, alguns mal-entendidos e maldades praticados pelos antagonistas acabam por afastá-los.

6 Apesar de Cabocla ser reprise no Vale a pena ver de novo, a novela foi produzida para o horário das 18 horas.

7 Audiência referente ao dia 28 de abril de 2008. 
Foram identificadas duas famílias extensas e chefiadas por mulheres, a de Dorotéia e a de Celeste. Alice e Valquíria, ambas protagonistas da novela, compõem uma família monoparental feminina, pois no início da história moravam com sua mãe. Como podemos ver na Tabela 3, a novela apresenta predominância de chefia feminina nas famílias que retrata.

Tabela 3 - Famílias da novela Amor e intrigas

\begin{tabular}{|c|c|c|c|c|c|c|}
\hline Chefe da família & Mãe & Pai & Filhos & Outros $^{8}$ & Chefia & Classificação \\
\hline Mãe das irmãs & $\begin{array}{c}\text { Não é apresentado } \\
\text { o nome. }\end{array}$ & - & Alice e Valquíria & - & Feminina & $\begin{array}{l}\text { Monoparental } \\
\text { Feminina }\end{array}$ \\
\hline Celeste & Celeste & - & Christina, Hugo e Pedro & $\begin{array}{c}\text { Petrônio } \\
\text { (Francisco) }\end{array}$ & Feminina & Extensa \\
\hline Dorotéia & Dorotéia & - & Débora e Felipe & Daniel & Feminina & Extensa \\
\hline
\end{tabular}

\section{Beleza pura}

A narrativa é baseada em clínicas de estética e salões de beleza, o que remete para o próprio nome da telenovela, Beleza pura (Tabela 4). A protagonista da história é Joana. A garota foi abandonada pela mãe (a personagem Sônia), que engravidou aos 16 anos. Joana sai do orfanato disposta a encontrá-la, porém, como Sônia está desaparecida, a jovem encontra apenas os seus irmãos (Klaus e Dominique) e Guilherme, que é quem está cuidando deles. Joana e Guilherme apaixonam-se, todavia terão que enfrentar Norma, a grande vilã da história.

Nessa novela, houve predominância de família unipessoal, uma vez que os personagens de Joana, Guilherme, Norma e Renato moram sozinhos e a história não faz menção às suas famílias. Foram identificadas ainda duas famílias monoparentais: a de Ivete, divorciada e a de Sônia, que é viúva.

Tabela 4 - Famílias da novela Beleza pura

\begin{tabular}{|c|c|c|c|c|c|c|}
\hline Chefe da família & Mãe & Pai & Filhos & Outros & Chefia & Classificação \\
\hline Guilherme & - & - & - & - & Masculina & Unipessoal \\
\hline Ivete & Ivete & $\begin{array}{c}\text { Betão (pai de } \\
\text { Anderson) }\end{array}$ & $\begin{array}{l}\text { Anderson } \\
\text { e Rakelli }\end{array}$ & - & Feminina & $\begin{array}{l}\text { Monoparental } \\
\text { Feminina }\end{array}$ \\
\hline Joana & - & - & - & - & Feminina & Unipessoal \\
\hline Norma & - & - & - & - & Feminina & Unipessoal \\
\hline Renato & - & - & - & - & Masculina & Unipessoal \\
\hline Sônia & Sônia & - & $\begin{array}{c}\text { Dominique e } \\
\text { Klaus }\end{array}$ & - & Feminina & $\begin{array}{c}\text { Monoparental } \\
\text { Feminina }\end{array}$ \\
\hline
\end{tabular}

\section{Cabocla}

Conta a história de Zuca, uma típica cabocla de Vila da Mata, que é noiva de Tobias. O noivado de ambos é abalado pela chegada de Luís Gerônimo, advogado que vai para a cidadezinha cuidar de sua saúde. Luís éprimo de Boanerges, políticoinfluente da região e inimigo de Justino, vilão da novela. Cabocla possui cinco famílias que formam os núcleos principais da trama.
Destas, três podem ser consideradas nucleares e duas monoparentais masculinas. É importante destacar que todas apresentam chefia masculina. As famílias classificadas como nucleares são as de Boanerges, Felício e Zé da Estação. Já as monoparentais masculinas são as de Justino e Joaquim. O cenário matrimonial da trama é bastante simples, pois nenhum personagemé divorciado ou possui filho fora do casamento. Os personagens de Justino e Joaquim são viúvos (Tabela 5).

8 Seção dedicada a sobrinhos, tios, avós e netos, entre outros parentes que morem juntos ou com outra família nuclear. 
Tabela 5 - Famílias da novela Cabocla

\begin{tabular}{|c|c|c|c|c|c|c|}
\hline Chefe da família & Mãe & Pai & Filhos & Outros & Chefia & Classificação \\
\hline Boanerges & Emerenciana & Boanerges & Belinha & - & Masculina & Nuclear \\
\hline Felício & Generosa & Felício & $\begin{array}{c}\text { Rosa, Tina } \\
\text { e Tobias }\end{array}$ & - & Masculina & Nuclear \\
\hline Joaquim & - & Joaquim & $\begin{array}{c}\text { Luís } \\
\text { Gerônimo }\end{array}$ & - & Masculina & Monoparental Masculina \\
\hline Justino & - & Justino & $\begin{array}{l}\text { Mariquinha } \\
\text { e Neco }\end{array}$ & - & Masculina & Monoparental Masculina \\
\hline
\end{tabular}

\section{Caminhos do coração}

Essa novela tem como tema a manipulação e a mutação genética. Sócrates, dono da Progênese, uma rede de hospitais, teve a filha Maria e a esposa sequestradas há muito tempo. Ele é o patriarca de uma grande família, da qual fazem parte seus irmãos Platão e Aristóteles, a cunhada Irma e os seus respectivos filhos. Maria cresce na família de Ana e Pepe sem saber que não é filha biológica do casal. Após ser acusada da morte de Sócrates, inicia uma vida de fuga, na qual conhece o policial federal Marcelo
Montenegro, que investiga o mistério por trás do surgimento de tantos mutantes.

O modelo predominante em Caminhos do coração (Tabela 6) foi o de família extensa. As famílias de Sócrates e Marcelo receberam essa classificação por possuírem mais de uma geração vivendo na mesma casa. Na residência de Sócrates, por exemplo, vivem os seus dois irmãos, uma cunhada e os filhos de ambos. $\mathrm{Na}$ de Marcelo, vivem sua mulher, sua filha, sua mãe e seu irmão. Foi identificada, ainda, uma família nucleare uma conjugada-fraterna. Mais uma vez, foi encontrado um número superior de famílias com chefia masculina.

Tabela 6 - Famílias da novela Caminhos do coração

\begin{tabular}{ccccccc}
\hline Chefe da família & Mãe & Pai & Filhos & Outros & Chefia & Classificação \\
\hline Eric & Helga & Eric & - & Ramon & Masculina & Conjugada-Fraterna \\
Marcelo & Mabel & Marcelo & Tatiana & Beto e Dalva & Masculina & Extensa \\
Pepe & Ana & Pepe & Maria Luz & - & Masculina & Nuclear \\
& Luz & Platão & $\begin{array}{c}\text { Regina e Cléo } \\
\text { Antônio, Danilo, } \\
\text { Rodrigo. }\end{array}$ & $\begin{array}{c}\text { Aristóteles, } \\
\text { Irma, Platão, } \\
\text { Regina, Cléo, Antônio, } \\
\text { Danilo e Rodrigo }\end{array}$ & Masculina & Extensa \\
& Irma & Aristóteles & & \\
& & & & &
\end{tabular}

\section{Desejo proibido}

Apresenta como cenário a década de 1930, com os coronéis, as famílias tradicionais e os ricos fazendeiros, típicos da época. A história começa quando Cândida, poderosa matriarca, vende suas terras a Chico Fernandes, em decorrência do declínio do café. Como forma de não abrir mão de seu patrimônio, ela oferece a mão de sua filha Isabel para Chico e dessa união nasce Henrique. Mais tarde, com a morte de Isabel, Chico casa-se com Ana, que encontra a pequena Laura, e Henrique vai morar com a avó.
Passados 20 anos, Henrique e Laura estão prestes a casar-se quando chega à cidade o jovem padre Miguel, designado pelo Vaticano para investigar os supostos milagres de uma imagem em pedra dentro de uma gruta. Miguel e Laura apaixonam-se, o que enfurece Henrique, que fará de tudo para separá-los.

Em Desejo proibido, os modelos de família mais encontrados foram o monoparental feminino e o monoparental masculino, com duas famílias cada. Foi identificada, também, uma família extensa e uma nuclear. Houve predominância de chefia masculina entre as famílias pesquisadas (Tabela 7). 
SANTOS, R. S. dos; JOHN, V. M.; GUERRA, C.

Tabela 7 - Famílias da novela Desejo proibido

\begin{tabular}{|c|c|c|c|c|c|c|}
\hline Chefe da família & Mãe & Pai & Filhos & Outros & Chefia & Classificação \\
\hline Cândida & $\begin{array}{c}\text { Cândida } \\
\text { (avó) }\end{array}$ & - & $\begin{array}{c}\text { Henrique } \\
\text { (neto) }\end{array}$ & - & Feminina & Monoparental Feminina \\
\hline Chico Fernandes & Ana & $\begin{array}{c}\text { Chico } \\
\text { Fernandes }\end{array}$ & Laura & Iracy & Masculina & Extensa \\
\hline Edith $^{9}$ & Cândida & Viriato & André & $\begin{array}{c}\text { Edith } \\
\text { (empregada) }\end{array}$ & Feminina & Monoparental Feminina \\
\hline Padre Inácio & - & - & - & $\begin{array}{c}\text { Padre Inácio } \\
\text { (padrinho) } \\
\text { Miguel } \\
\text { (afilhado) }\end{array}$ & Masculina & Monoparental Masculina \\
\hline Viriato & Magnólia & Viriato & $\begin{array}{l}\text { Eulália e } \\
\text { Florinda }\end{array}$ & - & Masculina & Nuclear \\
\hline
\end{tabular}

\section{Duas caras}

Retrata a desigualdade social brasileira, contrapondo a favela, a classe média e a elite carioca. A trama começa quando Maria Paula, ainda jovem, fica órfã e conhece Adalberto Rangel, por quem se apaixona e com quem se casa. Posteriormente, ela descobre que sofreu um golpe ao ser abandonada e roubada pelo então marido. Adalberto passa por uma série de cirurgias plásticas até tornar-se Marconi Ferraço, um respeitável empresário que terá como principal inimigo Juvenal Antena, líder da favela da
Portelinha, comunidade vizinha ao terreno do condomínio que Ferraço pretende construir.

O modelo de família mais identificado em Duas caras foi o nuclear (Tabela 8). Das oito famílias estudadas, quatro enquadram-se nessa classificação. Foram encontradas ainda duas monoparentais masculinas, uma monoparental feminina e uma extensa. Com exceção da única monoparental feminina, as demais possuem chefia masculina. $\mathrm{Na}$ trama, os personagens de Juvenal Antena, Branca e Misael são viúvos. Maria Paula e Célia Mara são divorciadas de Adalberto Rangel e Antônio, respectivamente.

Tabela 8 - Famílias de Duas caras

\begin{tabular}{|c|c|c|c|c|c|c|}
\hline Chefe da família & Mãe & Pai & Filhos & Outros & Chefia & Classificação \\
\hline Antônio & $\begin{array}{l}\text { Célia } \\
\text { Mara }\end{array}$ & $\begin{array}{c}\text { Antônio } \\
\text { João Pedro } \\
\text { (pai biológico) }\end{array}$ & Clarissa & - & Masculina & Nuclear \\
\hline Barreto & Gioconda & Barreto & $\begin{array}{l}\text { Barretinho e } \\
\text { Júlia }\end{array}$ & - & Masculina & Nuclear \\
\hline Hermógenes & - & Hermógenes & $\begin{array}{l}\text { Adalberto } \\
\text { Rangel }\end{array}$ & - & Masculina & $\begin{array}{c}\text { Monoparental } \\
\text { Masculina }\end{array}$ \\
\hline $\begin{array}{l}\text { João } \\
\text { Pedro }\end{array}$ & Branca & João Pedro & Sílvia & - & Masculina & Nuclear \\
\hline $\begin{array}{l}\text { Juvenal } \\
\text { Antena }\end{array}$ & - & $\begin{array}{l}\text { Juvenal } \\
\text { Antena }\end{array}$ & Solange & - & Masculina & $\begin{array}{c}\text { Monoparental } \\
\text { Masculina }\end{array}$ \\
\hline $\begin{array}{l}\text { Maria } \\
\text { Paula }\end{array}$ & $\begin{array}{l}\text { Maria } \\
\text { Paula }\end{array}$ & - & Renato & - & Feminina & $\begin{array}{c}\text { Monoparental } \\
\text { Feminina }\end{array}$ \\
\hline Misael & - & Misael & $\begin{array}{l}\text { Evilásio e } \\
\text { Gislaine }\end{array}$ & $\begin{array}{c}\text { Júlia e } \\
\text { Misaelsinho }\end{array}$ & Masculina & Extensa \\
\hline Waldemar & Gabriela & Waldemar & Maria Paula & - & Masculina & Nuclear \\
\hline
\end{tabular}

9 Edith, apesar de ser empregada, foi quem criou André, o que pressupõe uma relação mãe e filho. 


\section{Considerações finais}

O modelo mais presente entre as famílias retratadas pelas telenovelas foi o nuclear, arranjo esse ainda predominante (Tabela 9). Entretanto, como afirmado anteriormente, o mesmo vem perdendo espaço para outras composições, como a monoparental feminina e a unipessoal. A primeira, segundo o IBGE em 2006, representava 18,1\% das famílias brasileiras, $3 \%$ a mais que em 1996 . Fato que demonstra o crescimento significativo no número de famílias com chefia feminina sem a presença de cônjuge. Essa classificação apresenta números expressivos especialmente nas regiões metropolitanas, onde a cultura é mais flexível e, portanto, permite novos arranjos.
A PNAD de 2006 apontou ainda o crescimento de famílias unipessoais. Neste estudo, tal classificação foi encontrada apenas na novela Beleza pura, fato que vai de encontro às tendências da sociedade brasileira, como destacam os indicadores do IBGE.É importante ressaltar, também, que das cinco famílias monoparentais masculinas contabilizadas, três foram identificadas nas novelas de época, Cabocla e Desejo proibido. Por outro lado, as monoparentais femininas foram identificadas, em sua maioria, nas novelas contemporâneas.

É interessante observar que, mesmo nas novelas de época, o tamanho retratado das famílias é bastante similar ao que ocorre na atualidade, diferente das épocas a que se referiam. Em Cabocla,

Tabela 9 - Modelos de família encontrados nas telenovelas analisadas

\begin{tabular}{cc}
\hline Modelo de família & Total \\
\hline Conjugada-fraterna & 01 \\
Extensa & 06 \\
Monoparental feminina & 06 \\
Monoparental masculina & 05 \\
Nuclear & 08 \\
Unipessoal & 04 \\
\hline
\end{tabular}

por exemplo, as duas famílias centrais da trama têm três e quatro membros cada, o que se assemelha ao modelo identificado pelo levantamento do IBGE. Como se vê, mesmo quando trabalham temáticas ligadas a outros momentos históricos, pelo menos no que se refere à extensão das famílias, as telenovelas mantêm seu laço com a realidade cotidiana de modo a gerar a empatia e a verossimilhança, já apontadas anteriormente.

Foram contabilizadas trinta famílias nas seis histórias analisadas, as quais fazem parte dos núcleos principais das tramas. Ao pesquisar as novelas contemporâneas, chegamos ao resultado de $61,9 \%$ dos homens chefiando famílias contra 38,1\% das mulheres. Nas de época, são 77,1\% de homens à frente de suas famílias, em oposição às mulheres com $22,3 \%$. No entanto, deve-se levar em conta que, em todos os casos de mulheres como chefes de famílias nos folhetins eletrônicos analisados, nenhuma possuía cônjuge. Dado esse que se contrapõe aos indicadores sociais do IBGE, que informam uma porcentagem de $20,7 \%$ de mulheres que, mesmo casadas, desempenham o papel de gestoras de suas famílias.

Pode-se perceber que, nesse aspecto, as telenovelas ainda não mudaram. As famílias ainda são enfaticamente patriarcais, o homem permanece retratado como o provedor. Essa realidade só muda quando não há a presença do homem.

Esta pesquisa, assim como concluiu Fadul (1999) em seu estudo, não considera prudente estabelecer relações de causa e efeito entre as telenovelas e a realidade. Ambas influenciam-se e modificamse no decorrer dos tempos. Com base nas novelas analisadas, o que podemos afirmar é que, apesar de dialogar com a realidade e em certa medida procurar retratá-la em seus enredos, o que ficou claro pelo tamanho das famílias e por mudanças em suas composições, pode-se perceber que certos temas ainda parecem gerar um temor de recusa pela audiência. Isso se torna nítido ao não ser encontrada nenhuma família com orientação homossexual nos núcleos familiares considerados nas novelas analisadas, o 
que, embora já venha sendo abordado com mais frequência, ainda permanece como um grande tabu no que se refere à ideia e à composição de família nos "folhetins eletrônicos". Vale lembrar, porém, a exceção encontrada fora dos núcleos de protagonistas e que obteve grande aceitação popular: o trio formado por dois homens e uma mulher na novela Duas Caras, da Rede Globo. Dália, Bernardinho e Heraldo até tiveram um filho sob a responsabilidade compartilhada dos três pais. Como se vê, a telenovela não apenas ajuda a ditar ou influenciar costumes e comportamentos, mas também é diretamente influenciada pelas mudanças que vão ocorrendo na sociedade em que se insere. O quanto essa influência concretiza-se em comportamentos, só estudos de recepção podem nos ajudar a compreender. E esse é o próximo passo que pretendemos dar.

\section{Referências}

COSTA, C. A milésima segunda noite: da narrativa mítica à telenovela. São Paulo: Annablume, 2000.

ECO, U. Obra aberta: forma e indeterminação nas poéticas contemporâneas. São Paulo: Perspectiva, 1968.

ENGELS, F. A origem da família, da propriedade privada e do Estado. 13. ed. Rio de Janeiro: Bertrand Brasil, 1995.

FADUL, A. Telenovela e família no Brasil. In: CONGRESSO BRASILEIRO DE CIÊNCIAS DA COMUNICAÇÃO, 22., 1999, Rio de Janeiro. Anais... Rio de Janeiro: Congresso Brasileiro de Ciências da Comunicação, 1999. p. 315.

FERNANDES, I. Memória da telenovela brasileira. 4. ed. São Paulo: Brasiliense, 1997.

INSTITUTO BRASILEIRO DE GEOGRAFIA E ESTATÍSTICA - IBGE. Síntese de indicadores sociais: uma análise das condições de vida da população brasileira. Estudos e pesquisas. Informação Demográfica e Socioeconômica, n. 21, p. 252, 2007.

LOPES, M. I. V. de; BORELLI, S. H. S.; RESENDE, V. da R. Vivendo com a telenovela: mediações, recepção, teleficcionalidade. São Paulo: Summus, 2002.

MARCONI, M. de A.; PRESOTTO, Z. M. N. Antropologia: uma introdução. 5. ed. São Paulo: Atlas, 2001.
MARQUES DE MELO, J. As telenovelas da Globo: produção e exportação. São Paulo: Summus, 1988.

MARTÍN-BARBERO, J. Dos meios às mediações: comunicação, cultura e hegemonia. 2. ed. Rio de Janeiro: Ed. UFRJ, 2003.

SODRÉ, M. O monopólio da fala. Petrópolis: Vozes, 1977.

Recebido: 25/02/2010

Received: 02/25/2010

Aprovado: 24/04/2010

Approved: 04/24/2010 